\title{
A REDESCRIÇÃO DO FILÓSOFO: O IRONISTA LIBERAL
}

\author{
Edna Maria Magalhães do Nascimento ${ }^{1}$ \\ Júlio Gonçalves e Sá2
}

\begin{abstract}
Resumo:
O objetivo deste trabalho consiste em compreender o termo filosófico "ironista liberal" criado por Rorty que caracteriza a figura do pensador contemporâneo, imerso no mundo das redescrições. Pretende-se compreender neste artigo como Rorty descreve o teórico ironista. Sabe-se que ele usa um tipo particular de ironista. O filósofo ironista tem o papel de subverter os cânones da tradição platônica e kantiana, por isso, a teoria ironista tem também uma função terapêutica, isto é, compreender a força da narrativa metafísica cujo desejo é teorizar para que a filosofia possa se livrar totalmente desta tradição. A solução que Rorty apresenta para se opor a filosofia fundacionista e à filosofia do especialista tem no ironista liberal um ponto de apoio. Após a publicação de A Filosofia e o Espelho da Natureza (1979) Rorty se dedicou ao trabalho de redescrição do filósofo e apresentou a figura do 'ironista liberal'. Nessa redescrição o ironista liberal é aquele que entende que suas crenças e desejos mais centrais são contingenciais, rejeita o modelo de uma ordem dada para além do tempo e da mudança e não compreende a linguagem como "representação da realidade", mas enquanto vários jogos linguisticos. Esta guinada em direção a uma filosofia social, nos termos deweyanos, contém um forte apelo ético e humanista
\end{abstract}

Palavras-chave: Antirrepresentacionismo. Liberal. Ironista.

\section{THE PHILOSOPHER'S REDESCRIPTION: THE LIBERAL IRONIST}

\begin{abstract}
:
The objective of this work is to understand the philosophical term "liberal ironist" created by Rorty that characterizes the figure of the contemporary thinker, immersed in the world of redescriptions. It is intended to understand in this article how Rorty describes the theoretical ironist. It is known that he uses a particular type of ironist. The ironist philosopher has the role of subverting the canons of the Platonic and Kantian tradition, therefore, the ironist theory also has a therapeutic function, that is, to understand the strength of the metaphysical narrative, the desire to theorize, so that philosophy can get rid of totally from this tradition. The solution that Rorty presents to oppose the foundationalist philosophy and the philosophy of the specialist has in the liberal ironist a point of support. After the publication of Philosophy and the Mirror of Nature (1979) Rorty devoted himself to the work of redescribing the philosopher and introduced the figure of the 'liberal ironist'. In this redescription, the liberal ironist is one who understands that his most central beliefs and desires are contingent, rejects the model of an order given beyond time and change and does not understand language as "representation of reality", but as several linguistic games. This shift towards social philosophy, in Deweyan terms, contains a strong ethical and humanistic appeal
\end{abstract}

Keywords: Antirrepresentacionismo. Liberal. Ironista.

\section{Introdução}

1 Doutora em Filosofia pela Universidade Federal de Minas Gerais (2012). Pós-doutorado em Filosofia - Epistemologia Contemporânea, pela Universidade de Navarra - Espanha (2016/17). Atualmente é professora Associada, da Universidade Federal do Piauí, lotada no Departamento de Fundamentos da Educação DEFE/CCE. Integra o Programa de Pós Graduação em Filosofia - PPGFIL/UFPI e o Programa de Mestrado Profissionalizante PROF-FILO. Email: magaledna@yahoo.com.br

2 Mestre em Filosofia pela Universidade Federal do Piauí. Professor de Filosofia da Rede Pública de Ensino. Email: juliotutorfilosofia@gmail.com 
Ao situar um rol de autores considerados revolucionários porque transcenderam ao esquema mentalista da filosofia tradicional, Rorty concluiu que o trabalho filosófico que supostamente se coloca como área disciplinar, que tem a palavra final para todo o resto da cultura, deve ser abandonado. Em virtude dessa posição Rorty declara, "afirmo que Freud, Nietzsche e Bloom fazem por nossa consciência o que Wittgenstein e Davidson fazem por nossa linguagem, ou seja, exibem sua pura contingência" (RORTY, 2007, p. 55).

Rorty utiliza o termo edificante para se referir a um determinado tipo de filosofia que busca encontrar novas, melhores e mais interessantes maneiras de falar de nós mesmos e dos outros. Trata-se de uma filosofia cujos pensamentos são pautados na contingência das relações.

Os pensadores edificantes nos mostram a efemeridade humana em contraponto ao arcabouço metafísico que fora construído ao longo da história. Rorty poderia dizer que creditamos à razão uma supervalorização que desviou nosso entendimento daquilo que é realmente importante. Portanto, edificante é o pensar que se apoia em um projeto aberto ao diálogo com os vários ramos da cultura. Um pensador edificante, em sua opinião, seria um intelectual engajado em projetos culturais diversos e centrado na suspeita em relação às pretensões da epistemologia tradicional, opondo-se assim ao pensador sistemático ou epistemológico.

Nesse processo de redescrição da filosofia, Rorty caracteriza a filosofia da contingência pelo nome de edificante, mas observa que o termo apropriado seria "Bildung". Como o termo é alemão, poderia soar muito estrangeiro. Pensou também em usar o termo filosofia "educativa", mas poderia soar de modo prosaico. Portanto, edificante é aquele que educa pelo exemplo.

Dentre os filósofos edificantes Rorty cita Dewey, James, Heidegger, Wittgenstein, dentre outros. Tanto Heidegger quando Dewey, na leitura de Rorty, rejeitaram a distinção grega entre ação e contemplação, que resultou nas "ninhadas" de dualismos que alimentaram todas as instituições e forneceram os problemas da filosofia para os filósofos modernos. Se, de um lado, Dewey identificava a cisão entre ação e contemplação como resultante da relação social desigual entre o homem livre e o escravo, de outro lado, Heidegger reconhece que o

\begin{tabular}{|l|l|l|l|l|}
\hline Q Povista Dialectus & Ano 9 & n. 19 & Agosto - Dezembro 2020 & p. 289 - 304 \\
\hline
\end{tabular}


desmembramento da consciência originalmente unida provocou a fatalidade do Ser (RORTY, 1982).

Dessa maneira, Rorty concluiu que, os filósofos edificantes e terapêuticos tiveram que abandonar a visão moderna do conhecimento e da mente. Ao fazer isso, eles não forneceram um novo paradigma, mas indicaram novos motivos para se continuar filosofando. Eles deram à filosofia o status de ciência revolucionária na acepção de Thomas Kuhn, quando apresentaram novas formas de fazer filosofia, "novos mapas do território" e uma postura revolucionária no sentido de enfrentar a 'filosofia normal'. Para Rorty, isto significa a necessidade de abandonar a velha ontologia, de anular a epistemologia e a metafísica como disciplinas possíveis.

Após a publicação de "A Filosofia e o Espelho da Natureza" (1979) Rorty se dedicou ao trabalho de redescrição do filósofo e apresentou a figura do 'ironista liberal'. Na obra "Contingência, Ironia e Solidariedade" (1989) o ironista liberal é descrito como aquele que entende que suas crenças e desejos mais centrais são contingenciais. Este rejeita o modelo de uma ordem dada para além do tempo e da mudança e não compreende a linguagem como "representação da realidade", mas enquanto vários jogos linguisticos. Esta guinada em direção a uma filosofia social, nos termos deweyanos, contém um forte apelo ético e humanista.

\section{O ironista liberal e a contingência da linguagem}

Rorty descreve o intelectual e, até mesmo, o cidadão comum, como um "o ironista". Esta é a condição daquele que vive em uma sociedade liberal e se percebe dentro da contingência de seu vocabulário, de seu arcabouço moral, ou seja, de um repertório construído socialmente que representa um conjunto de palavras que justificam suas ações, suas crenças e sua vida.

A figura do "ironista liberal", caracterizada por Rorty, está respaldada no na proposta de liberal, no sentido mais progressista do termo, fundamentando-se na crença de que os 'liberais’ são as pessoas que pensam que a crueldade é a pior coisa que fazemos (RORTY, 2007, 134). Aliado ao termo 'ironista', Rorty acrescenta o vocábulo 'liberal' e, assim o descreve:

\begin{tabular}{|l|l|l|l|l|}
\hline Qevista Dialectus & Ano 9 & n. 19 & Agosto - Dezembro 2020 & p. $289-304$ \\
\hline
\end{tabular}


Tomo minha definição de "liberal" de Judith Shklar ${ }^{3}$, para quem liberais são as pessoas que consideram a crueldade a pior coisa que fazemos. Uso "ironista" para designar o tipo de pessoa que enfrenta a contingência de suas convicções e seus desejos mais centrais - alguém suficientemente historicista e nominalista para abandonar a ideia de que essas convicções e esses desejos centrais remontam a algo fora do alcance do tempo e do acaso. Os ironistas liberais são pessoas que incluem entre esses desejos, impossíveis de fundamentar, sua própria esperança de que o sofrimento diminua, de que a humilhação dos seres humanos por outros seres humanos possa cessar (RORTY, 2007, 18).

A redescrição do filósofo na condição de ironista liberal trata-se de uma inspiração que Rorty toma de empréstimo do pensamento de Shklar. Esta filósofa centrou-se em duas ideias principais: a "crueldade" como o pior mal e o "liberalismo do medo". O tema da crueldade foi apresentado do ensaio "Putting Cruelty First" publicado em Daedalus (1982) e em Ordinary Vices (1984). Quanto ao 'liberalismo do medo' a reflexão está exposta em um ensaio com o mesmo título, ocasião em que Shklar denuncia as "inevitáveis desigualdades de poder" que resultam da organização política.

O cerne deste liberalismo consiste na defesa de uma democracia constitucional, embora esteja sujeita a falhas, este modelo protege as pessoas dos abusos dos mais poderosos, restringindo o governo e dispersando o poder entre uma multiplicidade de grupos politicamente ativos. Assim como Shklar, Rorty acredita que diante dos vícios e das injustiças, o pensamento crítico deve ocupar esta lacuna baseando-se fortemente na literatura e na filosofia para se contrapor a todas as formas de injustiças e crueldade (SHKLAR, 1998).

Nosso autor discute como a ironia pragmática procuraria reconciliar-se com as exigências do liberalismo. Deste modo, ele esboça as pistas que nos conduziriam a uma "comunidade liberal utópica" marcada pela presença de indivíduos com características de “ironista liberal". O liberal diz respeito àquele que possui aversão a todo tipo de crueldade e defende a solidariedade. O ironista seria a pessoa livre das crenças em verdades estacionárias que estão sempre dispostas à redescrições da realidade. $\mathrm{O}$ "ironista liberal" tem a tarefa de autoconstrução, torna-se autônomo e autor de si.

Para Rorty, o ironista é a pessoa que tem dúvidas radicais e contínuas sobre o vocabulário final que ela atualmente usa, porque ficou impressionada com outros vocabulários, vocabulários tomados como definitivos por pessoas ou livros que encontrou; o ironista percebe

3 Judith Shklar (24 de setembro de 1928 - 17 de setembro de 1992), filósofa da Universidade de Harvard que se dedicou ao estudo da teoria política, notadamente a do período iluminista.

\begin{tabular}{|l|l|l|l|l|}
\hline Qevista Dialectus & Ano 9 & n. 19 & Agosto - Dezembro 2020 & p. $289-304$ \\
\hline
\end{tabular}


que o argumento formulado em seu vocabulário atual não pode nem subscrever nem dissolver essas dúvidas; (RORTY, 2007, 134).

Assim, filósofos de significância do século XX foram aqueles que se situaram no campo da imaginação e formularam utopias, rompendo assim com Platão e tendo a liberdade como reconhecimento da contingência. Assim, o autor declara que são esses filósofos que procuram desvincular a insistência de Hegel na historicidade do idealismo panteísta. Eles aceitam a identificação nietzschiana do poeta forte, do criador, do herói da humanidade, em vez do cientista que é tradicionalmente retratado como um descobridor (RORTY, 2007).

Rorty escreve que para definir com mais precisão o ironista, adotara três critérios condicionantes: Primeiro, será alguém que tem dúvidas radicais e continuas sobre o seu vocabulário final; segundo, que percebe que as argumentações contidas em seu vocabulário final não corroboram para desfazer tais dúvidas e, terceiro, esta pessoa não acha que seu vocabulário esteja mais próximo da realidade do que o de outra pessoa (RORTY, 2007, p. 134).

A formatação do novo vocabulário carece de cuidado ao trabalhar com os termos a serem redescritos, pela estima e apreço que o pronunciante tem do seu vocabulário final.

Todos os seres humanos carregam um conjunto de palavras que empregam para justificar seus atos, suas crenças ou convicções e sua vida. Trata-se das palavras com que formulamos elogios a nossos amigos e desprezo por nossos inimigos, bem como nossos projetos de longo prazo, nossas dúvidas mais profundas sobre nós mesmos e nossas mais altas esperanças. São as palavras com que narramos, ora em caráter prospectivo, ora retrospectivamente, a história de nossa vida. Chamo a essas palavras o "vocabulário final" de uma pessoa. (RORTY, 2007, p. 133).

Feito este esclarecimento Rorty argumenta que o ironista liberal é aquele que tem a tarefa de colocar em "xeque" a validade dos vocabulários finais.

\footnotetext{
Chamo tais pessoas de "ironistas" por seu reconhecimento de que qualquer coisa pode ser levada a parecer boa ou má, ao ser reescrita, e sua renúncia à tentativa de formular critérios de escolha entre vocabulários finais coloca-as na posição que Sartre chamava de "metaestável": nunca propriamente capazes de se levarem a sério, por estarem sempre cônscias de que os termos em que se descrevem são passíveis de mudança, e sempre cônscias da contingência e fragilidade de seus vocabulários finais e, portanto, de seu eu (RORTY, 2007, p. 134).
}

Corroborando com a ironia rortyana, Sousa (2009) explica que:

\begin{tabular}{|l|l|l|l|l|}
\hline Qevista Dialectus & Ano 9 & n. 19 & Agosto - Dezembro 2020 & p. $289-304$ \\
\hline
\end{tabular}




\begin{abstract}
A noção de ironia filosófica nos remete a Sócrates que, por meio de sua maiêutica, alertava os atenienses acerca da ilusão do conhecimento que estes julgavam possuir. Porém, contemporaneamente ela está associada a uma postura de descrença em relação à noção de verdade objetiva, postura essa expressada de forma bastante clara pelas críticas nietzschianas às noções de fato e verdade (SOUSA, 2009, p. 3).
\end{abstract}

O ironista liberal à maneira do cético, ao se deparar com teoria que se propõem ao absoluto, deve suspender os juízos para compreensão melhor da realidade, pois as descrições sobre o mundo são provisórias e contingenciais. Rorty, diz que o ironista liberal é consciente de sua incerteza quanto ao seu próprio vocabulário. Isto porque ele não acredita que seu próprio vocabulário forneça todas as respostas para suas dúvidas. Ademais ele não acredita ser possível se aproximar de algum tipo de 'certeza', como se fosse esta superior aos demais vocabulários (SOUSA, 2011). Conforme Rorty:

\footnotetext{
Em contraste, os ironistas não vêem a busca de um vocabulário final como sendo (nem mesmo em parte) um modo de entender corretamente algo distinto desse vocabulário. Não consideram que a ideia do pensamento discursivo seja conhecer, em nenhum sentido passível de ser explicado por noções como "realidade", "essência do real", "ponto de vista objetivo" e "a correspondência da linguagem da realidade". (RORTY, 2007, 137).
}

Vimos que os filósofos edificantes nos apresentam uma nova descrição do mundo ao ignorar os problemas tradicionais da filosofia. Edificam uma filosofia preocupada em compreender as relações contingenciais sem pretendê-las universais e eternas. A limitação temporal de cada geração lega a próxima aqueles problemas que já foram herdados de geração anteriores. O reconhecimento dessa limitação permite voltar-se para problemas mais imediatos, mas não menos importantes.

Muitos têm dificuldade de abandonar seu vocabulário final, alguns, simplesmente, não querem abandonar, mas o ironista reconhece que seu vocabulário está cheio de falhas e é extremamente limitado. Esse reconhecimento é o ponto de partida para a busca de um novo vocabulário. Para os ironistas, "vocabulário final" não significa "aquele que acaba com todas as dúvidas" ou "aquele que satisfaz nossos critérios de conclusividade, adequação ou otimização" (RORTY, 2007, 137).

Quando Rorty apresenta a metáfora do ironista ele pretende confrontar com o perfil do sujeito metafísico que acredita em essências eternas e imutáveis, pessoas que não encaram a contingência das suas próprias crenças e dos seus próprios desejos mais centrais. Diferente

\begin{tabular}{|l|l|l|l|l|}
\hline Qevista Dialectus & Ano 9 & n. 19 & Agosto - Dezembro 2020 & p. 289-304 \\
\hline
\end{tabular}


do metafísico, que tem a certeza e a verdade para promover e propagar, o ironista se sente meio que perdido neste mundo:

\begin{abstract}
O ironista passa o tempo preocupado com a possibilidade de se haver iniciado na tribo errada, de ter sido ensinado a jogar o jogo da linguagem incorreto. Preocupa-se com a possibilidade de que o processo de socialização que o transformou em um ser humano, ao lhe dar uma linguagem, tenha lhe dado a linguagem errada e, com isso, o tenha transformado no tipo errado de ser humano, mas não consegue fornecer um critério do erro (RORTY, 2007, 136).
\end{abstract}

O ironista está preocupado em compreender o mundo que lhe cerca com as limitações impostas pelo vocabulário que usa. O início da superação do vocabulário final é o reconhecimento dessas limitações, provocando uma inquietude algoz. Rorty propõem que essa superação nos torne seres humanos melhores. Malachowski reconhece a importância subversiva do termo ironista liberal, sobretudo, em virtude de esta postura filosófica enfrentar aqueles que vivem dos negócios da crueldade (2002).

A ironia no entendimento de Rorty deve encaminhar o interlocutor a questionar seu vocabulário que é confrontado pela redescrição. O vocabulário redescritivo está comprometido com a solidariedade. O grande desafio dessa proposição consiste na seguinte indagação: como seremos capazes de compartilhar nossas preocupações centrais com aqueles avessos a uma sociedade solidária e fraterna? Alguns são completamente alheios ao sofrimento e dor das pessoas, insensíveis às angustias humanas que levam a exploração e sofrimento.

A proposta do "vocabulário", no qual podemos explicar o conhecimento humano, o progresso científico e a mudança cultural, não recorre à compreensão da linguagem como mediadora entre sujeito e significados, as palavras com característica não linguísticas.

A tradição representacionista da linguagem dá preferência ao uso de frases únicas no lugar de vocabulários, relaciona o fato à exatidão e se pronuncia por sentença. Contudo, a proposta de Rorty estabelece que o vocabulário molda nossa fala e comportamento. Por isso, proporcionar uma descrição adequada de nossa história intelectual e cultural, exige completo manejo para ser entendido.

Para o ironista, as buscas de um vocabulário final não estão fadadas a convergir. Para ele, frase como "por natureza, todos os homens têm o desejo de conhecer" ou "a verdade independe da mente humana" são simples chavões usados para inculcar o vocabulário final local, o senso comum do ocidente. Ele só é ironista na medida em

\begin{tabular}{|l|l|l|l|l|}
\hline Qevista Dialectus & Ano 9 & n. 19 & Agosto - Dezembro 2020 & p. 289 - 304 \\
\hline
\end{tabular}




\begin{abstract}
que seu próprio vocabulário final não contém essas ideias. Sua redescrição do que faz, ao buscar um vocabulário final melhor do que aquele que utiliza atualmente, é dominada por metáforas de criação, e não de descoberta, de diversificação e ineditismo, e não de convergência para o que estava presente antes. Ele pensa nos vocabulários finais como realizações poéticas, e não como frutos de uma investigação diligente, de acordo com critérios previamente formulados (RORTY, 2007, p. 139).
\end{abstract}

Diferente da tradição, não há um modelo preestabelecido de fatos e acontecimento, previamente racionalizados que justificam toda a realidade. O ironista reconhece a limitação própria do ser humano, a relação de causa e efeito perde força de necessariedade que impacta o entendimento humano.

\title{
3. O ironista liberal e a redescriçao da política
}

Apresentamos o perfil do intelectual ironista que foi caracterizado como o pensador que assume a contingência de sua identidade, sabe-se periférico, adota para si um vocabulário que se materializa nas ações em defesa da solidariedade e contra as formas injustas de vida social. Agora, na redescrição filosófica, Rorty adentra o campo da política. Trata-se de um desdobramento natural da sua crítica à filosofia mentalista. A reflexão política realizada por Rorty considera essencial a ideia de se estabelecer uma comunidade que seja inclusiva em nível planetário. Trata-se de defender uma sociedade cuja premissa liberal nos livre das antigas e recentes autoimagens da filosofia.

O filósofo argumenta que de acordo com a razão iluminista, é possível identificar três pressupostos básicos do projeto moderno. Primeiro, a aposta na existência de um desejo universal pela verdade; segundo, a ideia de que a verdade é a correspondência com a realidade e terceiro, a noção de que esta última possui uma estrutura intrínseca. Para Rorty estas premissas só fazem sentido se forem articuladas a uma só, ou seja, "o interesse humano pela verdade oferece o motivo para criar uma comunidade includente" (RORTY, 2005, p. 104). Assim, o avanço e a disseminação das descobertas sobre a verdade, a ampliação do terreno comum partilhado, torna as sociedades mais tolerantes e solidárias. Os valores metafísicos de concepções supostamente verdadeiras e necessárias são substituídos por valores contingências, frutos da conversação e do entendimento das sociedades liberais.

\begin{tabular}{|l|l|l|l|l|}
\hline Qevista Dialectus & Ano 9 & n. 19 & Agosto - Dezembro 2020 & p. 289 - 304 \\
\hline
\end{tabular}


Rorty pensa que o compartilhamento amplo de determinados valores e crenças, em prol da sustentação de patamares mínimos de justiça e tolerância, consubstancia uma das tarefas mais importantes a cargo da contemporaneidade. Entretanto, Rorty é cético em relação à adoção de princípios universalistas, nesses assuntos é preferível ser francamente etnocêntrico e confessar a impossibilidade deste feito, descartando-se a fantasia de ter acesso a um fictício mundo da razão e da universalidade (RORTY, 2005).

Ora, o que parece politicamente mais viável é a utilização de um argumento honestamente estruturado a partir de um ponto de vista contingente, buscando enfatizar aspectos da própria experiência histórica que pode se revelar valiosa quando estendidas ou traduzidas a outras culturas. Ou seja, essa postura é mais exequível do que apostar em postulações que aspiram encarnar, de algum modo "objetivo", as ideias de racionalidade ou da justiça, das quais outras sociedades seriam carentes, absoluta ou relativamente (Rorty, 2005).

No âmbito da política liberal o que se pode vislumbrar e até estimular é a formulação de um vocabulário que mostre, por exemplo, mulheres e homens com possibilidades de mais facilmente aproximar-se uns dos outros, inclusive os que são diferentes e a desafiarem-se reciprocamente em termos dos seus específicos comprometimentos axiológicos, aqui ou em outras sociedades, como sujeitos possuidores de experiências ou história instrutivas e inspiradoras para relatar. O que é bem diferente de alguém que presume "fazer um melhor uso de uma capacidade humana universal" (Rorty, 1994, p. 123-124).

A concepção liberal discutida por Rorty deve criar condições para o progresso moral, uma vez que este trata mais "da ampliação das fronteiras da nossa imaginação" do que da consequência de obedecermos mais estritamente "a um imperativo independente de contexto" (Rorty, 2005, p. 226). Rorty acredita ser possível ampliar os limites da nossa comunidade de justificação, alargando o contingente dos que podem ser considerados inclusos, aos quais devemos lealdade. Então, pode-se concluir que o neopragmatista considera que a sociedade fundada na diversidade precisa articular a lealdade com a justiça, de maneira que o parâmetro de expansão da liberdade seja o sentimento de comunidade.

Rorty entende que não há contradição entre essa perspectiva e o seu localismo, porquanto "dizer que devemos trabalhar com nossos olhos, que devemos ser etnocêntricos, é simplesmente dizer que crenças sugeridas por outra cultura devem ser testadas pela tentativa de tecê-las juntamente com crenças que já possuímos" (RORTY, 2005, p. 114).

\begin{tabular}{|l|l|l|l|l|}
\hline Qevista Dialectus & Ano 9 & n. 19 & Agosto - Dezembro 2020 & p. 289 - 304 \\
\hline
\end{tabular}


Neste sentido, a sociedade que ele reivindica é a liberal utópica, ou seja, aquela capaz de recepcionar a consciência da contingência enquanto desdobramento do Iluminismo. Nesse sentido, agregará novas forças positivas advindas deste processo revolucionário, sobretudo, a solidariedade.

A proposta liberal de Rorty visa superar as velhas preocupações metafísicas (substância x acidente, realidade x aparência, absoluto x relativo), por um modelo que entende a mudança como constante, inclusive a mudança nas diversas instituições humanas. Por isso é preciso estabelecer a condenação a crueldade como inferência primeira no processo de redescrição.

\begin{abstract}
Há, portanto, duas diferenças entre o ironista liberal e o metafísico liberal. A primeira concerne ao sentido do que a redescrição pode fazer pelo liberalismo; a segunda, ao sentido da ligação entre a esperança pública e a ironia privada. A primeira diferença é que o ironista julga que as únicas redescrições que servem aos propósitos liberais são aquelas que respondem à pergunta "que é que humilha? ao passo que o metafísico também quer responder à pergunta "por que devo evitar humilhar? (RORTY, 2007, p.162).
\end{abstract}

Rorty com certeza está se referindo às formulações universalistas de uma ética da conversação, a exemplo daquela formulada por Habermas. Nesse sentido, ele apresenta o metafísico liberal como àquele que aspira que nosso desejo de sermos bons seja fomentado por um argumento que implique uma auto redescrição, no entanto, ainda considera uma essência humana comum, uma essência que seja algo mais do que a nossa capacidade compartilhada de sofrer humilhações. Ao contrário disto, o ironista liberal quer apenas que a probabilidades de sermos bons, de evitarmos humilhação do outro, sejam ampliadas pela redescrição. Ele acha que o reconhecimento de uma susceptibilidade comum à humilhação é o único vínculo social necessário. (RORTY, 2007, p.162).

Rorty argumenta que enquanto o metafísico liberal acha que o bom liberal tem o domínio de que algumas proposições cruciais são verdadeiras, o ironista liberal, ao contrário, acha que o bom liberal possui apenas o saber técnico especializado. Rorty prossegue afirmando que o primeiro pensa na cultura superior do liberalismo como centrada na teoria, enquanto o segundo vê esta cultura centrada na literatura, nas formas estéticas, ou seja, no sentido mais antigo e estreito da palavra, em peças, poemas e, sobretudo, em romances.

\begin{tabular}{|l|l|l|l|l|}
\hline Qevista Dialectus & Ano 9 & n. 19 & Agosto - Dezembro 2020 & p. $289-304$ \\
\hline
\end{tabular}


O metafísico liberal acha que a tarefa do intelectual é preservar e defender o liberalismo, respaldando-o com proposições verdadeiras sobre grandes temas, mas o ironista liberal acha que essa tarefa é aumentar nossa habilidade de reconhecer e descrever os diferentes tipos de pequenas coisas em que os indivíduos ou as comunidades centram suas fantasias e sua vida, portanto, ele quer observar os micros espaços políticos e consequentemente as contingências históricas e culturais (RORTY, 2007, p. 165).

O liberalismo rortyano se preocupa em evidenciar a contingência da linguagem, a contingência da individualidade e a contingência de toda comunidade humana como tal. Neste percurso, Rorty desenvolve uma temática ética envolvendo a redescrição deste novo sujeito cuja identidade de si mesmo se faz na contingência, na adoção de princípios fundamentais à vida democrática como os da não-indiferença e da solidariedade. Dessa maneira, a solidariedade é concebida como um desenvolvimento permanente para afastar a sociedade da crueldade promovida pela necessidade de satisfação de nossos desejos. A declaração de Rorty é muito ilustrativa quando afirma:

Parece bastante compatível com a afirmação de que estremecer de vergonha e indignação ante a morte desnecessária de uma criança - uma criança com quem não temos laços de família, tribo ou classe - é a mais alta forma de emoção que a humanidade atingiu, ao desenvolver as instituições sociais e políticas modernas (RORTY, 2007, 245).

A proposta de Rorty é que abandonemos a ideia de natureza humana e busquemos a realização de uma vida melhor, num esforço construtivo de nos tornarmos melhores do que somos. Para isso deve-se substituir a premissa universalista pela redescrição, pois não conseguiremos sair da linguagem usando juízos morais. Ou seja, o melhor é descrever nossas próprias experiências de modo alternativo, imaginativo, usando nosso vocabulário final como possibilidade de redescrever, de acessar sensibilidades, ressignificando e revendo nossas vidas e nossa identidade moral.

Portanto, Rorty se coloca contra todos os tipos de crueldade cometida contra qualquer ser humano, estendendo este termo para a crueldade contra todos os seres vivos (nãohumanos). Somente a solidariedade permite a reaproximação da filosofia com a realidade histórica e social. O pensador não pode mais se restringir a conceitos e enunciados, precisa compreender o mundo ao seu redor com todos os instrumentos necessários de intervenção para

\begin{tabular}{|l|l|l|l|l|}
\hline Qevista Dialectus & Ano 9 & n. 19 & Agosto - Dezembro 2020 & p. 289 - 304 \\
\hline
\end{tabular}


desenvolver uma sociedade com justiça social e o reconhecimento da pluralidade cultural como ponto de partida.

O ironista para Rorty deve emergir do solo de uma sociedade democrática. Portanto, quando o autor apresenta o perfil de um pensador como ironista ele se recusa a aceitar que este filósofo esteja comprometido com o conservadorismo social e com instituições anacrônicas do ponto de vista das conquistas e dos direitos adquiridos. Considerando este novo filósofo, Rorty articula a estratégia imaginativa dos pensadores revolucionários às contingências históricas da sociedade liberal. Dessa junção ele apresenta o vocabulário do que seria o ironista liberal, ou seja, aquele,

[...] fala sobre sociedade em termos dessa utopia liberal de equidade de oportunidade, e não possui um apoio filosófico como as leis da história, o declínio do ocidente ou a era do niilismo, ele está em posição de ser o que chamo de ironista. Um ironista é alguém que diz que uma utopia liberal não é algo que expressa à essência da natureza humana e da história. A vontade de Deus, mas é simplesmente a melhor ideia que as pessoas tiveram sobre o objeto para o qual trabalham. $\mathrm{O}$ ironismo, nesse contexto, significa algo próximo ao antifundacionalismo (RORTY, 2006, p.43).

Conforme Fávero (2014) Rorty compreende o filósofo como uma espécie de trabalhador braçal ou profeta, isto é, alguém capaz de mesclar a tarefa de limpar "certos resíduos" do passado e anunciar propostas futuras. Tal papel é semelhante ao que foi descrito por Bacon e Descartes, quando associavam o desejo de livrar-se de resíduos aristotélicos e incorporaram visões utópicas do futuro.

Para Rorty, é preciso que os filósofos parem de se preocupar com a autonomia da filosofia, pois isto significa, entre outras coisas, parar de querer estabelecer linhas muito claras para distinguir questões filosóficas de questões políticas, religiosas, estéticas ou econômicas (2000, p. 135). Com isso, a preocupação deixa de ser relativa aos temas da demarcação da filosofia. Por isso, não há mais lugar para a ideia de manter a filosofia num estado de pureza, ou de tratá-la como se fosse uma disciplina no topo da hierarquia disciplinar, mas o trabalho do pensamento seria o de construir pontes entre as nações e de tomar iniciativas cosmopolitas.

Para que isso ocorra, diz Rorty, os professores de filosofia precisam encontrar uma maneira de evitar três grandes tentações: "o anseio revolucionário de ver a filosofia como um agente de mudança, ao invés de vê-la como um agente de reconciliação; o anseio escolástico de confinar-se às fronteiras disciplinares; e o

\begin{tabular}{|l|l|l|l|l|}
\hline Qevista Dialectus & Ano 9 & n. 19 & Agosto - Dezembro 2020 & p. 289-304 \\
\hline
\end{tabular}


anseio chauvinista" (RORTY, 2000, p. 138). Tais tentações serão evitadas se adotarmos a concepção que Dewey tinha do papel e da função dos filósofos, a saber, "um trabalho de reconciliação do velho com o novo, e de nossa função profissional como sendo a de servir de intermediários honestos entre gerações, entre áreas de atividade cultural e entre tradições" (RORTY, 2000, p. 138).

O papel dos filósofos nessa redescrição assume uma espécie de cosmopolitismo multicultural e heterogêneo. O cosmopolitismo pensado por Rorty se associa a imagem de uma democracia planetária, uma sociedade na qual a tortura ou o fechamento de uma universidade ou um jornal nos causarão tanta revolta se acontecerem tanto do outro lado do mundo quanto em nosso país (RORTY, 2000, p. 139).

Os filósofos, para Rorty, não estarão produzindo sistemas e doutrinas, não estarão na vanguarda dessa utopia, mas ocuparão um papel periférico, menor, porém muito mais útil na sua criação. Farão o papel de mediadores entre a linguagem igualitária e as linguagens explicitamente discriminatórias de muitas tradições culturais diferentes. Trata-se, enfim, de uma função de persuadir homens e mulheres para que se tornem livres. Sendo assim, a grande função dos filósofos, segundo Rorty, é serem defensores da democracia.

\section{Considerações Finais}

Concluímos que o ironista é o pensador que se reconhece no âmbito da historicidade, sabe-se linguístico e prefere ser vistos como parceiro da conversação em que a sabedoria é pensada, não como argumentação, mas como amor, e cuja realização não consiste em encontrar o vocabulário correto para apresentar a essência, mas postular uma sabedoria prática necessária para participar de uma conversação.

O ironista adentra o campo da ética e da política sem pretensão de universalidade, para tanto um dos valores fundamentais do ironista é a capacidade de não-indiferença em relação ao sofrimento e a dor dos seres humanos, sejam eles próximos ou não. Rorty insiste que todos os filósofos deveriam continuar a grande conversação do Ocidente ao invés de ficar tentando solucionar os problemas tradicionais da filosofia moderna, este é um caminho para a filosofia antirrepresentacionista e como consequência para a reconstrução ou redescrição da atividade filosófica

\begin{tabular}{|l|l|l|l|l|}
\hline Qevista Dialectus & Ano 9 & n. 19 & Agosto - Dezembro 2020 & p. $289-304$ \\
\hline
\end{tabular}


Por fim, Rorty pensa que o compartilhamento amplo de determinados valores e crenças, em prol da sustentação de patamares mínimos de justiça e tolerância, consubstancia uma das tarefas mais importantes da atuação do filósofo na contemporaneidade.

\section{Referências:}

CARVALHO FILHO, A. Sensibilidade, solidariedade, autocriação privada. Rorty e a literatura. In: Redescrições. Ano I, Número Especial: Memória do I Colóquio Internacional

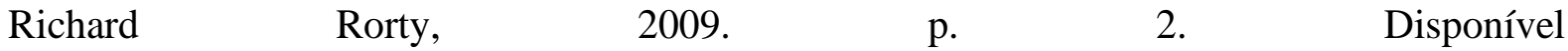
em:http://www.gtpragmatismo.com.br/redescricoes/redescricoes/memoria/aldir.pdf

CARVALHO FILHO, A.. A. A fraternidade, depois dos anos sombrios. A redescrição rortyana de uma consigna esquecida. IN: Panoramas do neopragmatismo rortyano para 'anos sombrios', Congresso Internacional "Revisitar Richard Rorty" com Robert Brandom, 2017.

DEWEY, John. Experiência e natureza. Trad. Murilo Otávio Rodrigues Paes Leme. São Paulo: Abril Cultural, 1980.

DEWEY, John. A arte como experiência. Trad. Murilo Otávio Rodrigues Paes Leme. São Paulo: Abril Cultural, 1980.

FÁVERO, Altair Alberto e TONIETO, Carina. O papel da filosofia na perspectiva de Richard Rorty: da epistemologia à hermenêutica. São Leopoldo, Revista Controvérsia. v. 10, n. 3, p. 143-149, set.-dez. 2014.

GHIRALDELLI JR., Paulo. Uma nova agenda para a filosofia. In: Pragmatismo e política. São Paulo: Martins Fontes, 2005.

JAMES, William. Ensaios do empirismo radical. Trad. P. R.Mariconda. São Paulo: Abril Cultural,1979.

KANT, Immanuel. A crítica da razão pura. Trad. Manuela Pinto dos Santos e Alexandre Fradique Morujão. 2 ed. Lisboa: Fundação Calouste Gulbenkian, 1979.

MALACHOWSKI, Alan. Richard Rorty. New Jersey: Princeton University Press, 2002. (Philosophy Now).

NASCIMENTO, Edna Maria Magalhães do. Dewey e Rorty: da metafísica empírica à metafísica da cultura. Teresina: EDUFPI, 2014.

\begin{tabular}{|l|l|l|l|l|}
\hline Gevista Dialectus & Ano 9 & n. 19 & Agosto - Dezembro 2020 & p. $289-304$ \\
\hline
\end{tabular}


NASCIMENTO, Edna Maria Magalhães do. Richard Rorty e seu Herói Filosófico: John Dewey. In: LIMA e ARAÚJO NETO (Org.). Filosofia prática, epistemologia e hermenêutica. Porto Alegre: Editora Fi, 2016, v. 01, p. 346-376.

OLIVEIRA, Manfredo A. Filosofia na crise da modernidade. São Paulo: Loyola, 1995.

PINTO, Paulo Roberto Margutti e MAGRO, Cristina (orgs.). Filosofia analítica, pragmatismo e ciência. Belo Horizonte: Editora da UFMG, 1998.

RAMBERG, Bjorn T. Rorty e os instrumentos da filosofia. In: PINTO, Paulo Roberto Margutti e MAGRO, Cristina (orgs.). Filosofia analítica, pragmatismo e ciência. Belo Horizonte: Editora da UFMG, 1998. p. 82-119.

RORTY, Richard. A filosofia e o espelho da natureza. Trad. Antônio Trânsito. Rio de Janeiro: Relume Dumará, 1994.

RORTY, Richard. A filosofia e o futuro. In: MAGRO, C.; PEREIRA, A. M. (Orgs.) Pragmatismo: a filosofia da criação e da mudança. Belo Horizonte: Editora UFMG, 2000. p. 125.

. Consequências do pragmatismo. Lisboa, editora Instituto Piaget, 1982.

Contingência, ironia e solidariedade. Trad. Vera Ribeiro. São Paulo: Martins Fontes, 2007.

Objetivismo, relativismo e verdade. Trad. Marco Antônio Casanova. Rio de Janeiro: Relume Dumará, 1997

Pragmatismo e política Trad. Paulo Ghiraldelli Junior.; revisão de tradução: Adriana de Oliveira. São Paulo: Martins, 2005.

Philosophy and social hope. NewYork: Penguin Books.1999.

RYLE; QUINE. et al. Ensaios. Trad. Baltasar Barbosa Filho (et al). São Paulo: Abril cultural, 1985.

SHKLAR, Judith. O liberalismo do medo. In: Pensamento Político e Pensadores Políticos. Chicago: Chicago University Press, 1998.

SOUSA, José Elielton de. Ironismo e tradição em Richard Rorty. Redescrições, v. 3, p. 1-10, 2009 .

TOLEDO JR, J.E.C de. Linguagem, contexto e razão. 2008. 173 f. Dissertação (Mestrado) Faculdade de Filosofia, Ciências Humanas. Departamento de Filosofia, Universidade de São Paulo. 2008

\begin{tabular}{|l|l|l|l|l|}
\hline Q Povista Dialectus & Ano 9 & n. 19 & Agosto - Dezembro 2020 & p. 289 - 304 \\
\hline
\end{tabular}


TOLEDO JR, J.E.C. Richard Rorty e a emergência da filosofia pós-analítica: transformações institucionais e mudança intelectual na filosofia profissional norte-americana contemporânea. Campinas - UNICAMP, 2015 (Tese de Doutorado). Faculdade de Filosofia, Ciências Humanas. Departamento de Filosofia, Universidade de São Paulo. 2008.

WITTGENSTEIN, Ludwig. Investigações filosóficas. Trad. José Carlos Bruni. 3 ed. São Paulo: Abril cultural, 1984.

\begin{tabular}{|l|l|l|l|l|}
\hline Qevista Dialectus & Ano 9 & n. 19 & Agosto - Dezembro 2020 & p. 289-304 \\
\hline
\end{tabular}

